\title{
INSAR ATMOSPHERIC DELAY MIGITIGATION BY GPS; CASE STUDY IZMIT EARTQUAKE INTERFEROGRAMS
}

\author{
M.U. Altın ${ }^{\mathrm{a}, *}$, E. Tari ${ }^{\mathrm{a}}$, L. Ge ${ }^{\mathrm{b}}$ \\ ${ }^{a}$ ITU, Civil Engineering Faculty, 80626 Maslak Istanbul, Turkey - (altinm, tari)@itu.edu.tr \\ ${ }^{\mathrm{b}}$ UNSW, School of Surveying and Spatial Inf. Sys., Kensington, NSW 2052, Australia ge@unsw.edu.au
}

KEY WORDS: GPS, SAR, InSAR, Troposphere,Turkey

\begin{abstract}
:
The Propagation delay when radar signals travel from the troposphere has been one of the major limitations for the applications of high accuracy Interferometric Synthetic Aparture Radar (InSAR). In this GPS data used for defining meteorological effects on radio signals. 1999 Izmit earthquake is chosen for the case study of tropospheric effects on InSAR images according to previous studies. Due to process of GPS data with BERNESE tropospheric delay model gained and compared with ROI PAC processed interferograms and it can easy figured out that the delay amounts are really reliable. As a result of this study, importance of atmospheric change in Turkey climate will be pointed out using SAR and GPS data integration with meteorological aspects.
\end{abstract}

\section{INTRODUCTION}

Earth sciences are developed in last decades with the development of space technologies especially in space geodesy and remote sensing. Global Navigation Satellite Systems (GPS) and remote sensing sensors are highly affected from these fast developments. As known space geodesy is based on electromagnetic waves and their reflection from earth surface. Variation in the refractive index of the atmosphere causes changes in the electromagnetic waves propagating through it. Therefore corrections of these atmospheric effects should be determined and applied with the assessed measurements. Atmospheric effects grouped in two types; ionospheric and tropospheric effects. Ionospheric effects can be removed by signal combinations during data processing. Tropospheric effects are directly related to troposphere and cannot be removed but can be modeled. The aim this of study is the correction of troposphere effects over Synthetic Aperture Radar (SAR) images and interferograms by using acquired GPS measurements in İzmit, Turkey.

Turkey is divided into seven regions due to socio-economical, administrative, climate and natural (soil, vegetation) similarities of related land. İzmit Province $\left(40^{\circ} 45^{\prime} \mathrm{N} 30^{\circ}\right.$ $\left.01^{\prime} \mathrm{E}\right)$ which is in Marmara Region. Marmara has the largest share in production and industry of Turkey. The area is just on the North Anatolian Fault (NAF), which extends from Karliova in Eastern Turkey to the Gulf of Saros in the Northern Aegean Sea, is one of the longest active strike-slip faults in the world with about $1500 \mathrm{~km}$ length and hit region 2 times with large earthquakes in 17 August and 12 November 1999 with 7.4 and 7.2 Mw. After these earthquakes Ziyadin Çakır and Rob Reilinger worked with the SAR data and publish papers by the help of these papers using InSAR technique for deformation monitoring to get more current insight in Turkey.(Çakir et al., 2003)(Reilinger et al., 2000)

\section{GPS AND SAR DATA}

The data for this study are GPS and ERS1/2 tandem SAR images before and after earthquake (12-13 August 1999 and 16-17 September 1999). GPS data is gathered form Marmara GPS Network (MAGNET) continuous operated GPS network which is designed and managed by TUBITAK Marmara Research Center and SAR images are taken from Dr. Ziyadin Çakır (Istanbul Technical University). (Figure 1)

Open source software is chosen for image and GPS data analysis. BERNESE software used for troposphere modeling due to capabilities of modeling time interval to get the more 


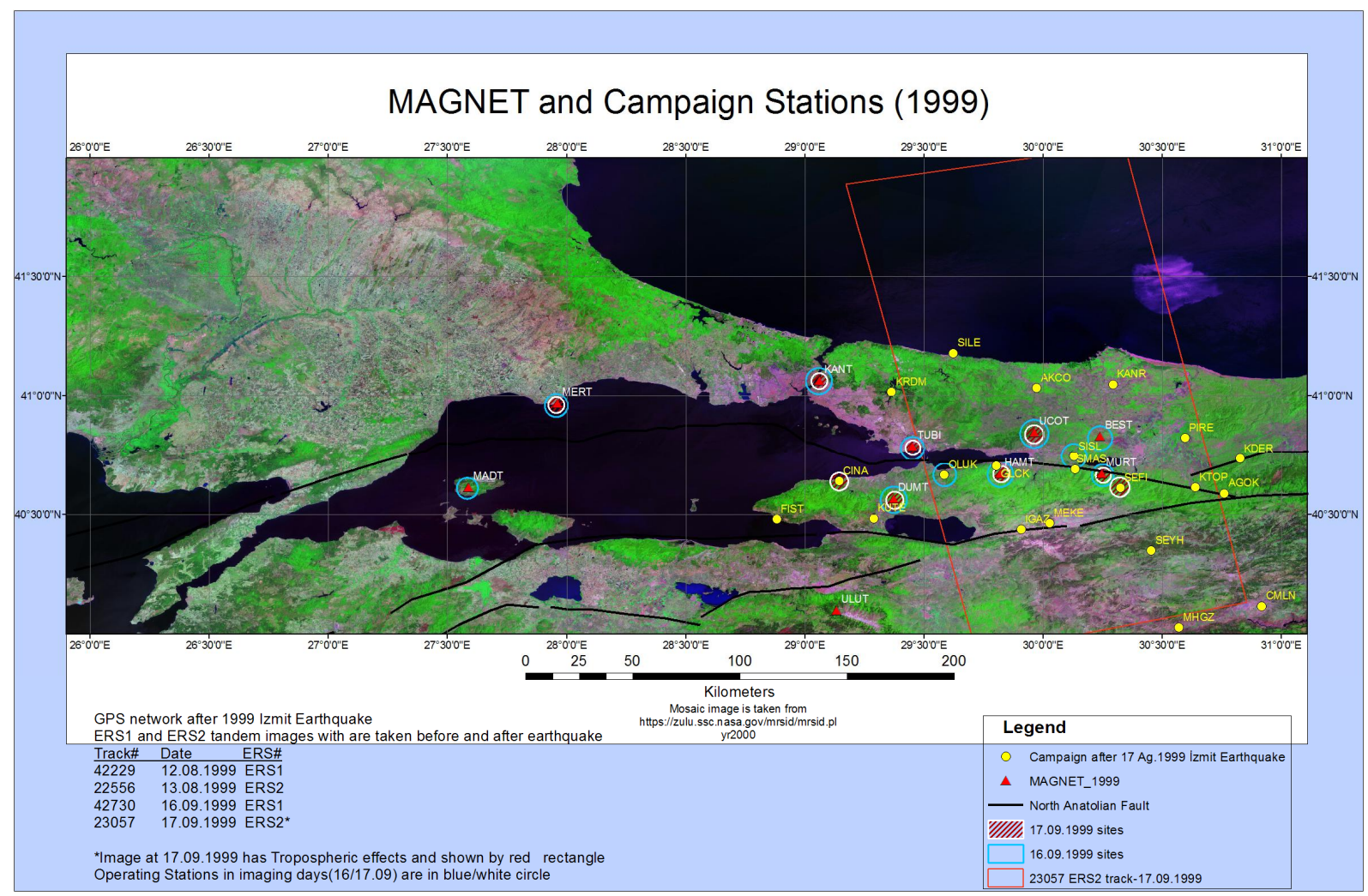

Figure 1. MAGNET and campaign sites after 1999 İzmit Earthquake red rectangle shows the ERS image boundary

accurate delay model of troposphere with 12 minutes.(Dach, Hugentobler, \& Walser, 2009) For SAR analysis ROI PAC software is used.(Rosen, Hensley, \& Peltzer, 2004).

GPS data for 17 September 1999 processed by using BERNESE software with 12 minutes interval for tropospheric delay. Every model and mapping function combinations used during processing. The main reason for this process is to produce a data set for deciding for which delay model will be used. A graph produced for 1 hour interval to see the changes, with data which Wet Neill mapping function is used. As shown graph (Figure.2) change in the values of different models are same and the values are close to each other except Hopfield Model. Hopfield delay values are less then the other models.

BERNESE processing of GPS data from Marmara Region shows us the variation in tropospheric delays which were considered as not significant for Turkey's atmosphere. 1 hour interval for tropospheric correction at zenith for "TUBI" station, IGS station which is located on Gebze, at 12 August 1999 changes between $10 \mathrm{~cm}$ and $25 \mathrm{~cm}$, the biggest difference is $14 \mathrm{~cm}$ in one hour from 16:00-17:00 (GMT). By using mapping functions we can easily calculate the amount of delay for incident angle of SAR image. According to Ziyadin Çakır and friends (2003) the tropospheric effects mentioned in 16 September and 17 September ERS tandem image pairs. This troposphere error causes errors up $14 \mathrm{~cm}$ (range change). Processing the GPS data which is obtained from TUBITAK Marmara Research Center for the imaging days, with 12 minutes interval of tropospheric delay estimation for $23^{\circ}$ (icident angle of ERS image) by mapping function (wet Neill Model andNeill Mapping Function) the mentioned region in Çakır et al. 2003 analyzed for tropospheric effects. Two main interpolation method is used, Kriging and Inverse Distance interpolation. For both techniques the delay differences between tandem days is 14$20 \mathrm{~cm}$ interval (Figure.3). So research findings are 


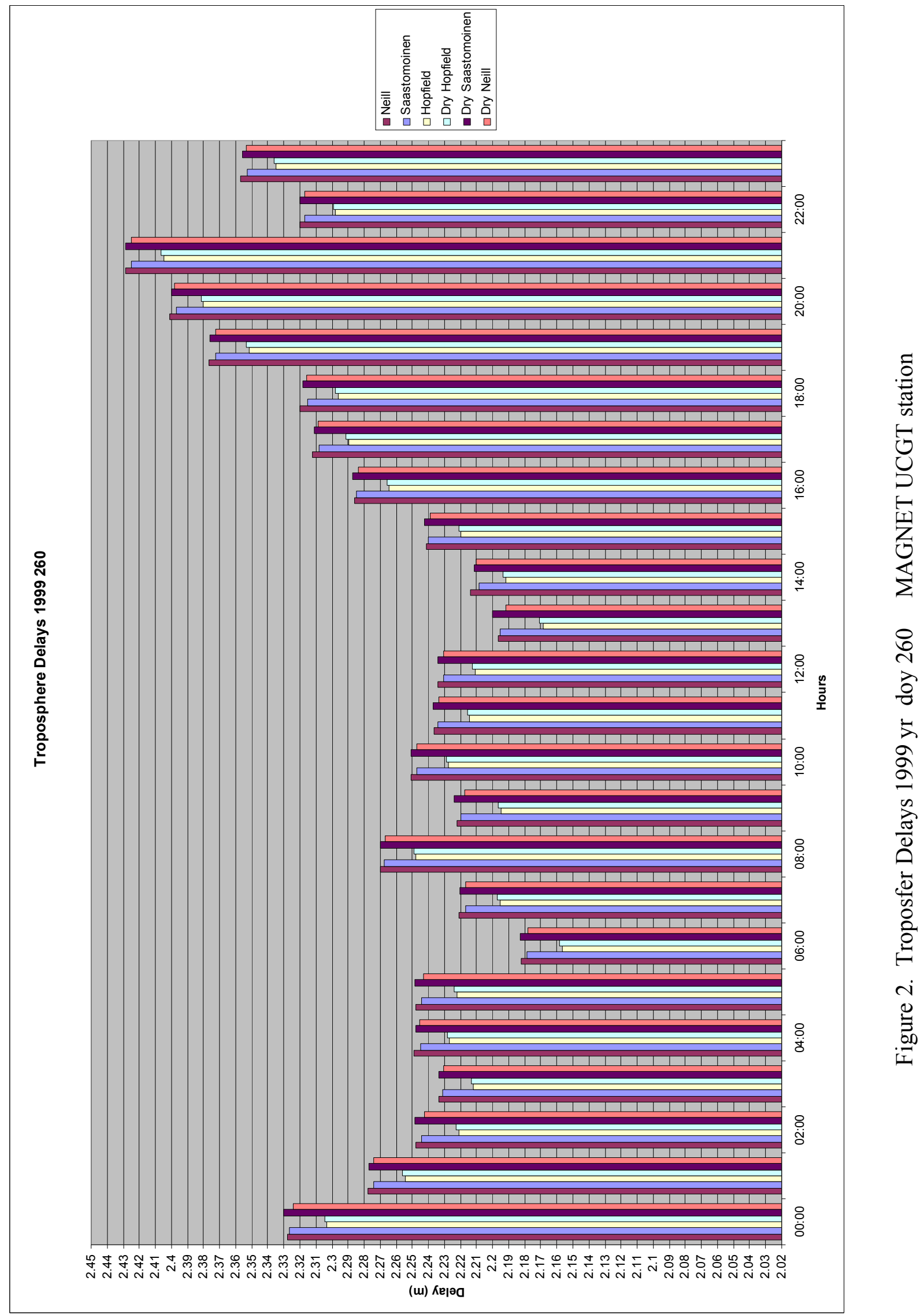




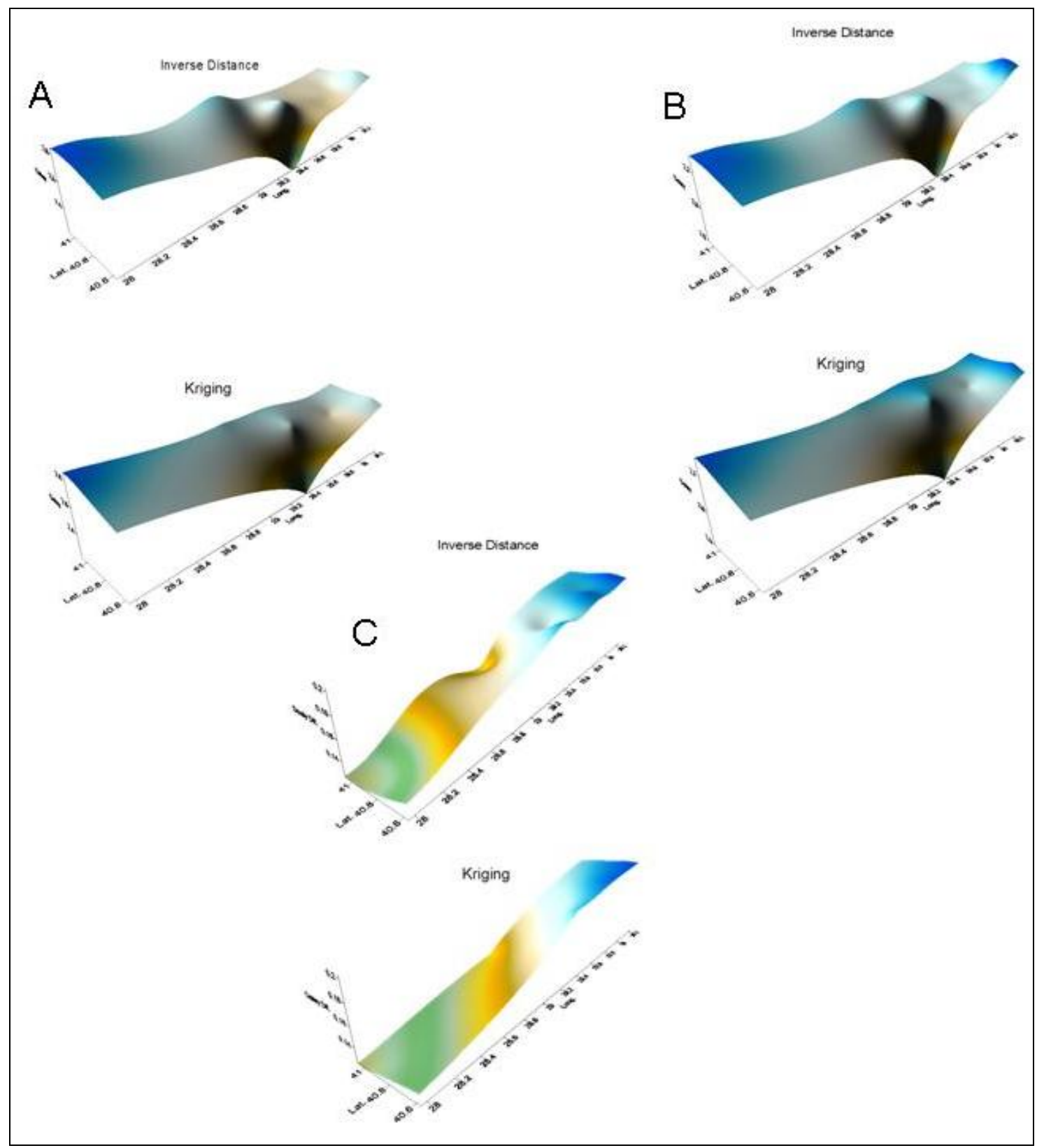

Figure 3. Troposperic Delays for ERS1/2 images (imaging time 16-17 September 1999 20:14). A) 16 September $199920: 12$ Tropospheric delays B) 17September 1999 20:12 Tropospheric delays C) 17-16 September 1999 20:12 delay differences

are show that the research can be useful for Turkey conditions. SAR image processing is done by ROI-PAC software. Images given by Dr. Çakır are belonging to 12-13 August 1999, 16-17 September 1999 with 157 track 797 frame number and 13 August 1999, 17 September 1999 with 157 track 815 frame number. Finally 2 pass interferograms are produced from image pairs of ERS1/2. As expected troposphere delay results are obtained again as in Çakır et. al
2003, which is also corrected by Meteorological data; NOAA DMSP images acquired on 16 and 17 September 1999.

16-17 September tandems processed by us due to recognize only the troposphere delays without seismic fringes on the image.(Figure 4). 


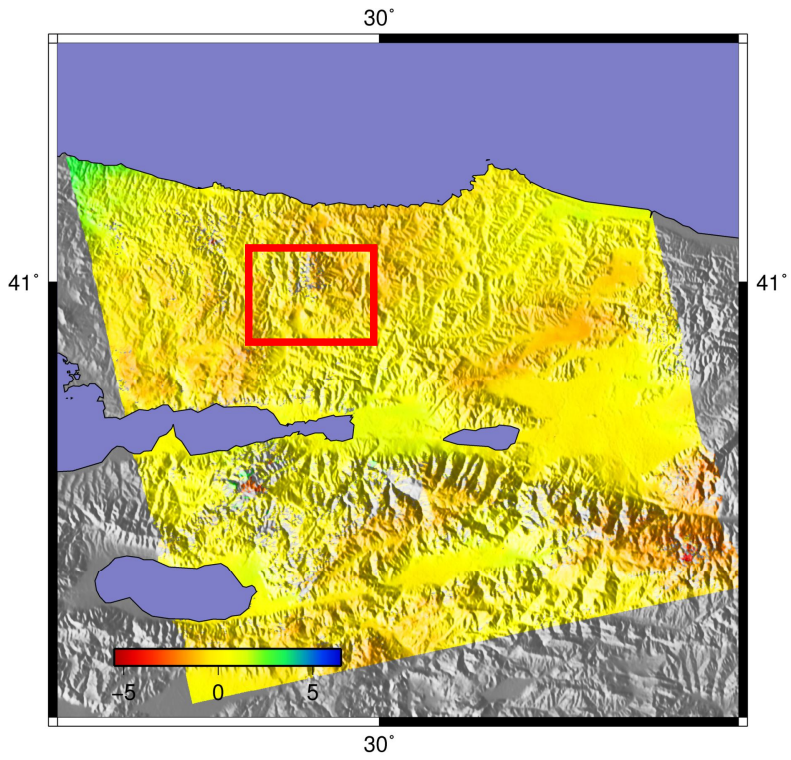

Figure 4. 17-16 September 1999 ERS Interferogram. Area in red rectangle effected by tropospheric delay

According to these results it can be said that troposphere delays can be really effective on radio signals not only GPS signal but also the RADAR signals. Delay difference amount for tandem imaging days for selected data can be reach up to $20 \mathrm{~cm}$ to from $14 \mathrm{~cm}$. This results shows us the importance of delay in SAR processing, mainly interferograms can be affected by any kind of tropospheric turbulence which cause errors on height information in the most accurate technique for finding changes in height, InSAR.

\section{CONCLUSION}

By taking into the consideration of region characteristics, best fitted delay model for the region will be determined and used in this study. An automatic flow or algorithm will be created for integration of these delays with the SAR images for fast and accurate correction. Tools like ArcGIS or MATLAB will be used for automatic correction flow or a Graphical User Interface (GUI) obtained using MATLAB.

As a result of this study, importance of atmospheric change in Turkey climate will be pointed out using SAR and GPS data integration with meteorological aspects. The importance of CORS networks and densities for atmospheric observations will be evaluated for Turkey. Also it will helpful for further atmospheric and InSAR studies over Turkey and (MAGNET) about potential earthquakes like Istanbul earthquake (predicted as $\mathrm{Mw}=7$ ).

\section{References}

Dach, R., Hugentobler, U., \& Walser, P. (2009). Bernese GPS Software Version 5.0 Tutorial. Processing. Bern: Astronomical Institute, University of Bern.

Reilinger, R. E., Ergintav, S., Bürgmann, R., McClusky, S., Lenk, O., Barka, A., Gurkan, O., et al. (2000). Coeseismic and Postseismic Fault Slip for the 17 August 1999, M=7.5, Izmit , Turkey Earthquake. Science, 289, 1519-1524.
Rosen, P., Hensley, S., \& Peltzer, G. (2004). Updated repeat orbit interferometry package released. Eos, Transactions, 85(5), 47. Retrieved from $\mathrm{http}$ //europa.agu.org/?uri=/journals/eo/v085/i005/200 4EO050004.xml\&amp;view=article

Çakir, Z., Chabalier, J.-B. D., Armijo, R., Meyer, B., Barka, A., \& Peltzer, G. (2003). Coseismic and early postseismic slip associated with the 1999 Izmit earthquake (Turkey), from SAR interferometry and tectonic field observations. Geophysical Journal International, 155(1), 93-110. doi:10.1046/j.1365246X.2003.02001.X 